\title{
Programas de Transferência Condicionada de Renda na América Latina: uma abordagem comparada entre Brasil, México, Chile e Colômbia
}

Pedro Luiz Costa Cavalcante

\section{Introdução}

O artigo se propõe a desenvolver um estudo comparado qualitativo acerca da implementação das políticas de transferência condicionada de renda na América Latina. Na última década, seus impactos sobre a melhoria das condições de vida da população têm chamado a atenção não apenas de instituições e autoridades do Brasil, mas também de organismos multilaterais, do meio acadêmico internacional e de governos de outras regiões. Todavia, a literatura específica tem se focado predominantemente na análise dos seus impactos e menos nos fatores relativos à operacionalização dos programas, ou seja, a implementação da política pública.

A literatura há décadas enfatiza as dificuldades da implementação efetiva de políticas públicas em função da complexidade da ação conjunta. Estudos clássicos como de Pressman e Wildavsky (1973) e Bardach (1977) ressaltam que, mesmo quando atores concordam em cooperar no início do processo de 
implementação, em função da convergência de objetivos comuns, isso não implica no sucesso da política, uma vez que não envolve um único momento de decisão, mas múltiplos. Nesse sentido, a análise das regras e modelos de funcionamento dos Programas de Transferência Condicionada de Renda (PTCR) ${ }^{1}$, em especial sob a ótica da relação intergovernamental, é fundamental, haja vista seus reflexos sobre aspectos basilares dessas políticas públicas, tais como o processo de identificação dos beneficiários, o acompanhamento das condicionalidades e a permanência das famílias nos programas.

Por isso, o objetivo principal do artigo é descrever as estruturas de funcionamento dessas políticas. Para fins de comparação foram selecionados os programas dos governos nacionais do Brasil, México, Chile e Colômbia, haja vista que consistem nas experiências mais importantes e consolidadas da região. O trabalho se baseia em parâmetros que envolvem os objetivos dos programas, seus critérios de inclusão e exclusão das famílias, formas de benefícios e, sobretudo, a estratégia de gestão compartilhada.

\section{A política de Transferência Con- dicionada de Renda}

Nas últimas duas décadas, as políticas de transferência de renda vêm ampliando espaço no debate acadêmico e na agenda governamental, constituindo-se como importante eixo dos sistemas de políticas sociais da América Latina. Tais políticas se configuram de diversas formas. As transferências condicionadas de renda são consideradas a mais nova geração das políticas sociais. Em termos gerais, esse tipo de política pública compartilha três componentes básicos: transferência monetária direta ao cidadão ou família, foco nos segmentos mais pobres da população e existência de condicionalidades. Como contrapartida os beneficiários devem cumprir uma agenda de atividades (BASTAGLI, 2009). Outro aspecto importante desses programas é a possibilidade de articulação no decorrer da sua implementação, seja de forma horizontal, com as demais políticas sociais, seja vertical, com outras esferas de governo. Assim, a multisetorialidade e a descentralização da gestão também são características do modelo padrão de transferência condicionada de renda.

Embora a implementação dessa modalidade de política seja recente, principalmente nos países em desenvolvimento, o debate do tema sobre garantia de renda mínima é bem mais antigo. Suplicy (2002) defende que a discussão teve início ainda no começo do século passado:

Depois da Primeira Guerra Mundial, na Europa e em outros continentes, alguns economistas começaram a procurar soluções que compatibilizassem ideias de liberdade, igualdade, eficiência, justiça e democracia [...] na década de 60, o debate se intensificou, tanto que economistas renomados como John Galbraith, James Tobin, entre outros, encaminharam um manifesto ao Congresso norte-americano em favor da adoção de um sistema de complementação e garantia de renda (Suplicy, 2002).

O apoio a esse tipo de política pública agrega acadêmicos de diferentes vertentes ideológicas, como o economista liberal Milton Friedman ${ }^{2}$, que se mostra preocupado com questões como liberdade e autonomia das pessoas, e outros mais envolvidos com bandeiras históricas da esquerda como a equidade e a distribuição 
de renda, como é o caso de Van Parijs ${ }^{3}$ (Suplicy, 2002; Suplicy e Cury, 1993; Licio, 2004).

A temática em boa medida bebe na fonte do debate acerca da justiça, mais especificamente a discussão da filosofia política de justiça distributiva. Nesse contexto, vale mencionar as contribuições de John Rawls (1971) e Amartya Sen (1982). $\mathrm{O}$ primeiro defende a necessidade de a sociedade contemporânea incorporar um conjunto de princípios de justiça, como o da igualdade. Trata-se de promover ao menos a adoção de um conjunto de igualdades justas de oportunidades para que o indivíduo tenha condições de perseguir seus objetivos pessoais. Focado justamente nas situações de desigualdades sociais, Amartya Sen demonstra em Poverty and Famines: $A n$ Essay on Entitlement and Deprivation (1982) que a questão da fome está não apenas relacionada à falta de alimentos, mas também a outros aspectos de ordem socioeconômica. De modo a superar esse círculo vicioso, Sen (1985) propõe a abordagem de capacidades (capabilities approach) que contrapõe a visão tradicional da economia e, em termos gerais, enfatiza a necessidade de superação da pobreza mediante o fomento das capacidades funcionais dos indivíduos. As situações de privação dessas capacidades estariam vinculadas a uma série de fatores, tais como ignorância, opressão política e carência de recursos financeiros.

Tais ideias e respectivas propostas influenciaram vários países desenvolvidos, no século passado, a adotar medidas de garantia de renda mínima. Do mesmo modo, atualmente vivenciamos uma tendência de proliferação nos países em desenvolvimento (BRitTo, 2005; Bastagli, 2009). Na América Latina 18 países já adotam essas políticas, na África 36, enquanto que na Ásia e no Pacífico esse número chega a 16 , conforme monitoramento do Centro de Política Pública Internacional para o Crescimento Inclusivo (IPC-IG) ${ }^{4}$.

As políticas vêm ganhando destaque em função de seus impactos na melhoria dos indicadores sociais, tais como frequência escolar, ampliação do atendimento à saúde, do combate à desnutrição (SOARES, Ribas e Osório, 2007; MDS, 2007); e, principalmente, devido a seus reflexos na redução da pobreza e desigualdade (SOARES, Ribas E Osório, 2007; MDS, 2007;

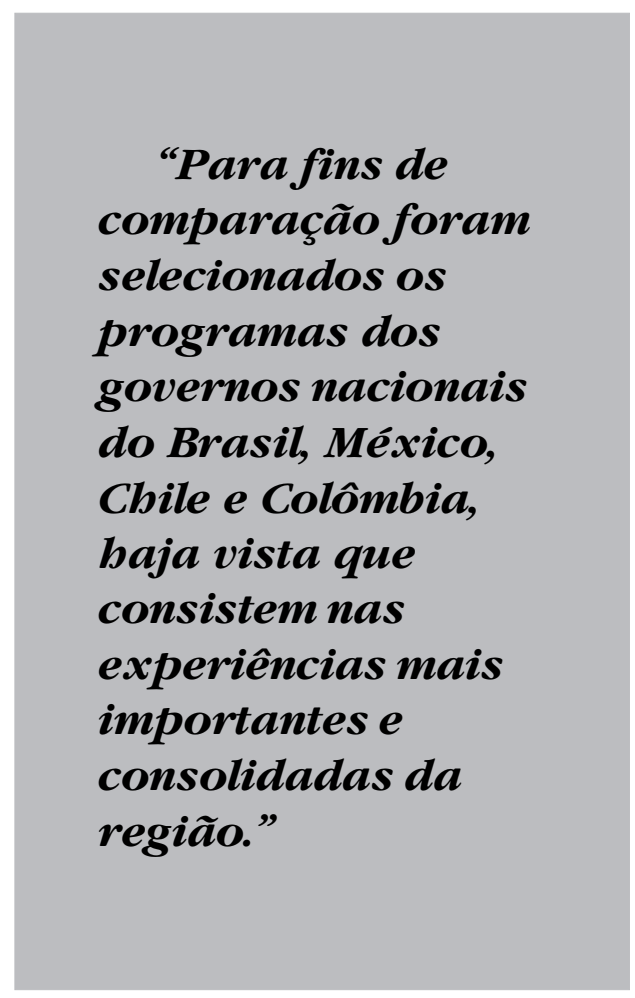

Lidert, Skoufias e Shapiro, 2006; Medeiros, Britto e Soares, 2008).

Embora compartilhem os componentes básicos do modelo de TCR e a finalidade precípua de combater a miséria e, indiretamente, promover uma melhor distribuição de renda ${ }^{5}$, tais experiências são bem diversificadas. Todavia, em todas elas, boa parte do sucesso do programa está 
relacionada aos modelos de implementação, haja vista que em praticamente todos esses resultados se pressupõe efetiva cooperação e coordenação intergovernamental. Nos tópicos seguintes são apresentados o desenho e a estratégia de implementação dos programas nacionais de TCR do Brasil, México, Chile e Colômbia.

\section{Implementação dos TCR na América Latina}

Os países da América Latina são pioneiros entre os emergentes na adoção de Programas de Transferência Condicionada de Renda. As políticas iniciadas em meados dos anos 90 encontram-se em diferentes níveis de implementação e também de abrangência, reflexo da evolução do debate sobre renda mínima dentro de cada país. A fim de descrever essa complexa configuração, o artigo se fundamenta nos seguintes eixos de análise para traçar uma abordagem comparativa entre os programas selecionados: objetivos dos programas, critério de elegibilidade e permanência das famílias, valores dos benefícios, público-alvo, dispêndio orçamentário, condicionalidades e, principalmente, estratégia de coordenação e cooperação entre os atores envolvidos.

\section{Programa Bolsa Família}

O Programa Bolsa Família $(\mathrm{PBF})^{6}$, criado em 2003, é resultante de um processo de unificação dos procedimentos de gestão e execução das ações vigentes de TCR do governo federal ${ }^{7}$. Ele tem como objetivo oferecer proteção a todo grupo familiar e contribuir para seu desenvolvimento. Para tanto, fundamenta-se em três dimensões. Primeiro, a promoção do alívio imediato da pobreza a partir da transferência direta de renda. Segundo, o reforço ao exercício de direitos sociais básicos nas áreas de saúde, educação e assistência social por meio do cumprimento das condicionalidades. E, por fim, a integração com programas complementares, que visa auxiliar e capacitar as famílias de modo que os beneficiários consigam superar a situação de vulnerabilidade e pobreza (Cohn E Fonseca, 2004).

Atualmente, constitui a maior política pública de TCR da América Latina, tanto em orçamento quanto em cobertura ${ }^{8}$. Atende à totalidade de famílias pobres do Brasil, ou seja, cerca 12,5 milhões de famílias em todos os municípios do país (24\% da população brasileira), com dispêndio de mais de 12 bilhões de reais (US\$ 6,6 bilhões), cerca de 0,4\% do PIB 9 . O programa atende à família em duas faixas de renda: com renda per capita mensal menor que $\mathrm{R} \$ 70,00$ e outra com renda mensal entre $\mathrm{R} \$ 70,00$ e $\mathrm{R} \$ 140,00$ por pessoa, caso possuam crianças ou adolescentes de até 17 anos. Os repasses monetários incluem um benefício básico de R\$ 68,00 (US\$37) para famílias na primeira situação e benefícios variáveis para crianças de até 15 anos: de R\$22 (US\$ 12) por criança - máximo de três - e R $\$ 33,00$ (US\$ 18) por adolescente - máximo de dois. $\mathrm{O}$ foco é no núcleo familiar e não no indivíduo, embora haja a priorização da figura materna como responsável pelo recebimento do benefício.

De acordo com Lindert et al (2007), a atração pelo Bolsa Família se deve a uma série de motivos, entre eles: eficiente experiência de unificação dos programas de TCR; magnitude e rápida expansão, o que o torna o maior programa desse tipo no mundo; impressionante precisão da focalização; impactos positivos comprovados na 
redução da pobreza e da desigualdade; papel do PBF na integração de políticas sociais, tanto de forma horizontal entre setores, quanto verticalmente entre níveis de governos.

Um ponto central desses resultados é a forma como o programa é operacionalizado dentro de uma perspectiva de cooperação envolvendo todos os níveis de governo, principalmente nas atividades de cadastro das famílias, gestão de benefícios e acompanhamento das condicionalidades.

No que tange à identificação e cadastramento das famílias, o Ministério do Desenvolvimento Social e Combate à Fome (MDS), responsável pelo programa em nível federal, atua principalmente em conjunto com os municípios. Estes, por sua vez, atuam no mapeamento e inserção dos dados familiares no Cadastro Único, bem como na provisão dos serviços básicos de saúde e educação. A partir dessas informações e da disponibilidade de vagas dentro da estimativa de pobreza do município, a família que atende aos critérios de elegibilidade pode ser incluída no programa que é atualizado mensalmente. $\mathrm{O}$ cadastro deve ser atualizado de dois em dois anos, e caso a família continue na faixa de renda, o benefício permanece vigente. Os estados desempenham papel auxiliar de apoio técnico e de monitoramento dos municípios. O pagamento dos benefícios é operacionalizado pela Caixa Econômica Federal, que é um banco federal com canais de pagamento em todas as municipalidades do país. A família realiza mensalmente a retirada do benefício por meio de cartão de saque individualizado.

Em relação às condicionalidades, estas constituem os compromissos das famílias nas áreas de educação, saúde e assistência social para continuar recebendo o benefício. $\mathrm{Na}$ educação, todas as crianças e adolescentes entre 6 e 15 anos devem estar matriculados e com frequência escolar mensal mínima de 85\% da carga horária. Já os estudantes entre 16 e 17 anos devem ter frequência de, no mínimo, 75\%. Esse acompanhamento é realizado pelos governos municipais e estaduais, que preenchem as informações no Sistema de Frequência Escolar do Ministério da Educação. $\mathrm{Na}$ área de saúde, as famílias beneficiárias assumem o compromisso de acompanhar o cartão de vacinação e o crescimento e desenvolvimento das crianças menores de 7 anos, enquanto as mulheres na faixa de 14 a 44 anos também devem fazer acompanhamento e, se gestantes ou nutrizes (lactantes), devem realizar o pré-natal e o acompanhamento da sua saúde e da do bebê. O registro de informações de acompanhamento de saúde é realizado pela prefeitura no Sistema de Vigilância Alimentar e Nutricional (Sisvan) do Ministério da Saúde. Por fim, na assistência social, a condicionalidade envolve crianças e adolescentes com até 15 anos, em risco ou retiradas do trabalho infantil pelo Programa de Erradicação do Trabalho Infantil (Peti), que devem participar dos Serviços de Convivência e Fortalecimento de Vínculos (SCFV) do Peti e obter frequência mínima de $85 \%$ da carga horária mensal.

O não cumprimento das condicionalidades reflete na aplicação de uma série de sanções que variam desde a simples notificação na primeira ocorrência até o cancelamento do benefício no quinto descumprimento.

Essas atividades retratam a capacidade da execução local em monitorar o atendimento de tais serviços públicos de forma articulada com as respectivas secretarias responsáveis. De modo a criar condições operacionais nos governos subnacionais, o MDS criou um índice de gestão 
descentralizada que avalia a execução local do PBF no tocante ao cadastro e condicionalidades, e, de acordo com o desempenho, são transferidos recursos financeiros para os estados e municípios mensalmente.

\section{Oportunidades do México}

O programa de TCR do governo federal mexicano é o mais conhecido internacionalmente e foi criado inicialmente sob o nome de Programa de Educação, Saúde e Alimentação (Progresa) em 1997. Com foco no combate à pobreza extrema e na redução da evasão escolar e das taxas de mortalidade materna e infantil, o Oportunidades, a partir de $2002^{10}$, passou a incluir novos elementos e ampliar sua cobertura de 300 mil famílias para cerca de 5,8 milhões de famílias atualmente $(23 \%$ da população mexicana). O orçamento federal do programa gira em torno de 3,6 bilhões de dólares ou cerca de $0,4 \%$ do PIB $^{11}$ (BASTAgLi, 2009).

O público-alvo são famílias com crianças em situação de extrema pobreza e que predominantemente residam em áreas rurais (86\%). Assim como no PBF, também se prioriza as mães das famílias como responsáveis pelo recebimento do benefício. $\mathrm{O}$ processo de mapeamento e inclusão ocorre em três fases: classificação de municípios em cinco categorias, de acordo com um índice de marginalidade econômica e social; definição de domicílios dentro de cada município mediante o método estatístico de análise de discriminantes; por fim, verificação junto à comunidade se a lista de nomes selecionados reflete a realidade da localidade. Após essas etapas, em cerca de cinco meses, inicia-se o pagamento do benefício (SoAres et al, 2007; Bastagli, 2009).

Os benefícios financeiros são pagos bimestralmente por meio de instituições bancárias e possuem três componentes: um incondicional para idosos acima de 70 anos no valor de US\$23, e dois condicionais de educação e de nutrição e saúde. O primeiro é pago como bolsa de estudo por dez meses (período letivo) e varia de 11 a 69 dólares por criança, de acordo com o nível educacional. Além disso, caso complete o ensino médio, o aluno recebe uma poupança de US\$300. Na área de saúde e alimentação, a família é contemplada com um pacote básico de serviços de saúde e também um benefício de US\$16 mensais ou bimensais para ajudar na complementação nutricional de crianças menores de cinco anos e/ou lactantes.

Assim como o Bolsa Família, o Oportunidades pressupõe um complexo arranjo de coordenação e cooperação que envolve secretarias federais de saúde, educação e desenvolvimento social, bem como governos estaduais e municipais; embora o financiamento do programa também seja de responsabilidade restrita do governo nacional. A coordenação do programa é vinculada à pasta do desenvolvimento social que preconiza o caráter intersetorial e intergovernamental da implementação.

No que tange às condicionalidades, estas são monitoradas pelos coordenadores estaduais e envolvem as áreas de educação e saúde. Na primeira, é obrigatória a matrícula das crianças entre 8 e 18 anos e também a frequência mínima de $85 \%$; enquanto na saúde, o compromisso familiar é visitar determinado número de vezes os centros de saúde, no caso de famílias com crianças até cinco anos, grávidas e lactantes. Estas últimas devem ainda frequentar cursos de educação alimentar.

O cumprimento das condicionalidades precede o pagamento dos benefícios e, na situação de descumprimento, as sanções 
variam desde suspensão dos benefícios até o cancelamento do benefício na terceira ocasião. Por fim, o benefício deve ser revalidado após três anos, podendo continuar por mais um ano nas áreas urbanas e mais três nas rurais.

\section{Chile Solidario}

O programa de TCR chileno, criado em $2002^{12}$, é parte do sistema de proteção social do país voltado à erradicação da extrema pobreza. O Chile Solidario apresenta caráter intersetorial bastante significativo, principalmente pelo fato dos seus beneficiários também constituírem público-alvo prioritário de outras políticas como habitação, trabalho e justiça, por exemplo.

A percepção é que a pobreza é tratada como um problema multidimensional que deve ser enfrentado por meio de ações complementares (Villatoro, 2005). Nesse sentido, além da ligação com outras políticas, o PTCR envolve as seguintes ações: o Puente - a entrada da política; o Vínculo - voltado aos idosos; o Calle para os moradores de rua; o Caminos para crianças com pais na prisão; o Programa de Habitabilidad (habitação); além do Programa de Producción Familiar para el Autoconsumo (segurança alimentar).

O programa atende a totalidade de famílias extremamente pobres, isto é, cerca de 300 mil ou $6 \%$ da população chilena, sendo $50 \%$ chefes de família do sexo feminino. $\mathrm{O}$ dispêndio da política gira em torno de 0,1\% do PIB, de acordo com dados desse mesmo ano (BAstagli, 2009). Portanto, observa-se uma abrangência e investimento consideravelmente mais modestos do que o Bolsa Família e o Oportunidades.
A transferência monetária é realizada por meio do programa Puente, direcionado prioritariamente às donas de casa, com duração máxima de dois anos e decréscimo do benefício a cada seis meses. O valor inicial, independente da composição ou tamanho familiar, era em 2006 de pouco mais de 20 dólares, chegando a seis dólares no último semestre. Este último também é o valor do benefício das famílias

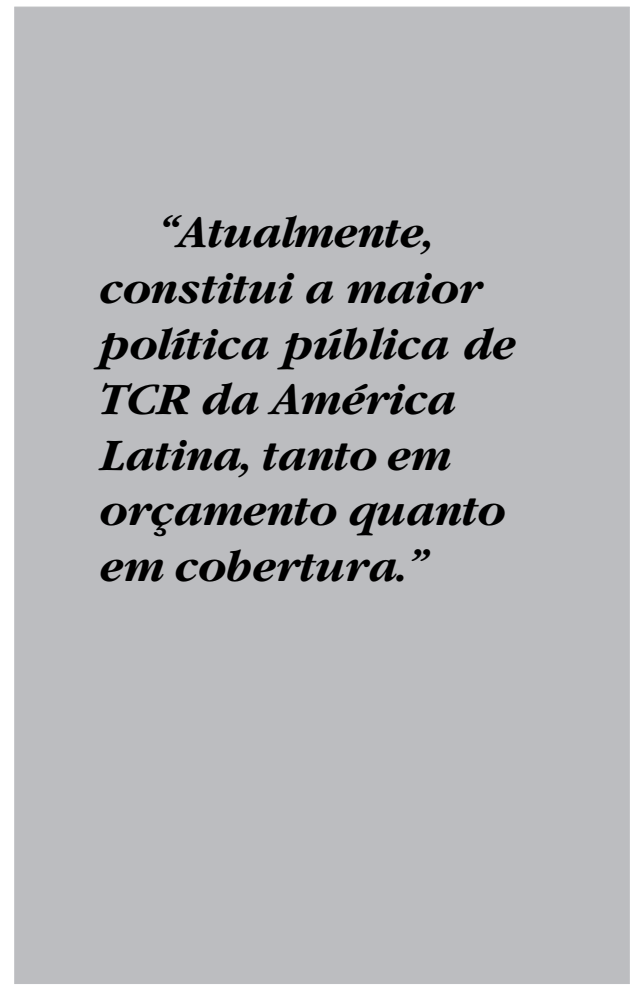

que permanecem por mais três anos no programa (Bono de egreso).

O processo de seleção das famílias se baseia nas informações de ordem socio-econômica das famílias, que incluem 13 variáveis em quatro dimensões (habitação, educação, emprego e renda). Tais informações são consolidadas na denominada Ficha de Protección Social e utilizadas para calcular o índice que posiciona 
a família de acordo com seu grau de vulnerabilidade.

Quanto ao arranjo institucional, o Ministério do Planejamento e Cooperação é o principal responsável pela política, que delega à Secretaria Executiva do Chile Solidario, a sua gestão. Além do apoio de outras pastas, o programa conta com a participação voluntária de Unidades de Intervenção Familiar e Rede de Intervenção Local no nível municipal, bem como da coordenação regional realizada nas províncias. É importante destacar que diferentemente do Brasil e México, o país é um Estado unitário, isto é, boa parte do poder político é concentrada no governo central. Dessa forma, a participação dos governos subnacionais na implementação dessa política se apresenta na prestação dos serviços de proteção social que, mesmo em um regime unitário, também pressupõe a descentralização de recurso e competências para os municípios.

Em relação às condicionalidades, os beneficiários devem participar de atividades monitoradas por visitas domiciliares que procuram avaliar a qualidade de vida com base em sete dimensões: saúde, educação, condições habitacionais, emprego, renda, dinâmica familiar e identificação. Entretanto, assim como as outras políticas de TCR descritas, o Chile Solidario também penaliza a família com o fim do pagamento do benefício em caso de não cumprimento dos compromissos.

\section{Familias en Acción - Colômbia}

O programa colombiano foi criado no ano de 2000 diante da necessidade de reduzir o impacto das crises econômicas que afetaram o país na segunda metade da década de 90. O desenho atual do programa foi elaborado em 2006 e compõe um conjunto de ações da rede de proteção social e combate à pobreza, também denominada de Juntos. Em síntese, a política se propõe a promover a inclusão efetiva de famílias pobres na estrutura dos serviços públicos prestados pelo Estado e assim torná-las capazes de superar a situação de pobreza. Para tanto, o programa se fundamenta em três eixos principais:

a) Integração e coordenação da oferta de serviços públicos no nível local;

b) Provisão de apoio familiar e comunitário temporário;

c) Geração de um conjunto de corresponsabilidades das famílias beneficiárias para que elas possam superar a pobreza.

Em 2009, o programa cobria cerca de 630 mil famílias em situação de extrema pobreza ( $5 \%$ da população), embora a meta seja atingir 1,5 milhão no fim de 2010. A política está presente em mais de $70 \%$ das municipalidades e possui um orçamento de cerca de 0,1\% do PIB. Quanto à focalização, a prioridade é atingir os $20 \%$ dos domicílios mais pobres em cidades com menos de 100 mil habitantes e com infraestrutura de educação, saúde e bancária. Além disso, a preferência é por famílias compostas por crianças de 0-17 anos. O processo de seleção se fundamenta no Sistema de Seleção de Potenciais Beneficiários para Programas Sociais (Sisben), que computa a pontuação considerando as condições de vida e as características do domicílio.

Os benefícios variam de acordo com o perfil das cidades (grandes ou não), com o nível educacional e idade das crianças e adolescentes. A transferência para fins de educação varia de seis dólares ao mês por criança em escola primária a 11 dólares por 
adolescente no ensino médio. $\mathrm{Na}$ área da saúde, o subsídio nutricional gira em torno de 15 dólares para crianças de 0-7 anos.

No que tange à implementação, a responsabilidade do programa é do Departamento Administrativo da Presidência, que descentraliza para as unidades de coordenação regionais e municipais. $\mathrm{O}$ pagamento é realizado por bancos locais diretamente aos beneficiários. O ciclo operacional se assemelha ao modelo do PBF em termos de envolvimento dos municípios (VILlatoro, 2005), que também formalizam a participação no programa e a partir daí passam a se responsabilizar pelas atividades locais, inclusive com complementação do valor do benefício. Ademais, Familias en Acción compõe a política social do governo colombiano que possui forte caráter intersetorial, incluindo a participação de 15 instituições governamentais e também do setor privado.

Quanto aos compromissos das famílias, também chamados de corresponsabilidades, consistem em três componentes: educação - frequência mínima de $80 \%$ das crianças de 7 a 18 anos; saúde - visitas clínicas que variam de acordo com a idade da criança; e saúde e educação da família - as mães devem comparecer a encontros e sessões de treinamento organizados no nível municipal. O monitoramento das condicionalidades é realizado anualmente e repercute no pagamento do subsídio. Por fim, os benefícios são automaticamente cancelados após cinco anos de permanência no programa.

\section{Considerações finais}

O presente artigo procurou descrever aspectos basilares dos principais programas de TCR da América Latina, de modo a possibilitar a comparação entre suas formulações e estratégias de execução. Nesse sentido, a preocupação não foi detalhar o processo de inserção na agenda governamental ou seus resultados, mais sim discernir de forma objetiva os pontos em comum e distintos de cada modelo de implementação, fenômeno este de certa forma negligenciado pela literatura.

Primeiro, observa-se que todos os programas compactuam a percepção de que a pobreza é um problema multidimensional e, portanto, seu enfrentamento demanda ações de caráter intersetorial. Logo, em todos os casos analisados, o combate à pobreza caminha em paralelo com iniciativas nas áreas de educação, saúde e nutrição, bem como habitação, assistência social e trabalho. Os objetivos convergem com a necessidade de atacar por diversas frentes as precárias condições de vida da população nesses países.

Outro aspecto semelhante é o públicoalvo, os segmentos mais pobres da população. A novidade é que, assim como no Brasil, os demais programas também atendem ao núcleo familiar com priorização da figura materna como responsável pelo recebimento do benefício. Com relação à abrangência, apenas o Brasil e o México atingiram a universalização do atendimento às famílias em situação de pobreza, o que se reflete no alcance de mais de $20 \%$ da população desses países. Entretanto, nos outros dois países, os níveis de cobertura das políticas são bem mais modestos. Enquanto no Chile isso é reflexo do foco restrito à população em situação de extrema pobreza ou miséria, na Colômbia, o Familias en Acción é mais recente e ainda encontra-se em processo de expansão.

No que tange aos critérios de inclusão no programa, ou elegibilidade, também nota-se certa variação, embora prevaleça a 
priorização dos mais carentes. As diferenças existem, sobretudo em relação à forma como são inseridas as famílias. As estratégias incluem desde métodos simples como o PBF, no qual o critério central é a renda per capita, a procedimentos mais sofisticados, como o caso chileno, que utiliza um índice composto de 13 variáveis socioeconômicas. Quanto aos critérios de permanência da família, eles podem variar de dois anos, como no Chile Solidario, a tempo indeterminado, a exemplo do beneficiário do PBF que continue vivendo na faixa de renda contemplada.

Ademais, em todos os programas de TCR analisados, a implementação pressupõe estratégias de coordenação e cooperação entre os atores múltiplos, sejam esferas de governo ou diferentes ministérios. Cabe considerar que essas participações variam consideravelmente, em especial nas experiências do Chile e Colômbia, que são estados unitários e, portanto, seus governos subnacionais não possuem autonomia como no Brasil e México. Do mesmo modo, as atividades desses entes também não são uniformes; enquanto em alguns países eles são responsáveis apenas pela provisão de políticas complementares, em outros, os governos subnacionais podem atuar também no cadastramento das famílias e no acompanhamento das condicionalidades. Estas, por sua vez, incluem uma gama de atividades, entre as quais predominam as áreas de saúde e educação.
Por fim, foi possível demonstrar que os arranjos de implementação das políticas de TCR são bastante diversificados, variando de acordo com os objetivos pretendidos, grau de importância da temática na agenda e arcabouço institucional de cada nação. Todavia, dois pontos merecem destaque. Primeiro, embora os valores dos benefícios não sejam altos em comparação ao salário mínimo, e nem os custos das políticas sejam tão representativos no orçamento desses países, os programas têm impactado na redução da pobreza, desigualdades e em outros indicadores sociais. Segundo, os programas em diferentes níveis, não abrem mão da implementação intersetorial e descentralizada, o que indica consenso nos governos latino-americanos em relação à importância da cooperação e coordenação para o alcance dos objetivos planejados.

Com efeito, é possível perceber que tais iniciativas representam uma nova fase das políticas sociais, na medida em que se pautam na ruptura do caráter particularista e clientelista, que por muito tempo marcou a administração pública da região. Além disso, seus bons resultados também demonstram ser fruto de modelos sofisticados de implementação que preconizam a gestão compartilhada e, assim, conseguem abranger de forma efetiva os segmentos populacionais historicamente excluídos.

(Artigo recebido em abril de 2011. Versão final em agosto de 2011).

\section{Notas}

${ }^{1}$ Esse tipo de política pública possui uma diversidade de denominações. Para fins dessa pesquisa, optou-se pelo termo Transferência Condicionada de Renda - TCR, adotado pelo Centro Internacional de Políticas para o Crescimento Inclusivo (IPC-IG), antigo Centro Internacional de Pobreza. O IPC-IG é uma parceria entre o Grupo de Pobreza do Departamento de Políticas de Desenvolvimento, o PNUD e do Governo do Brasil. 
${ }^{2} \mathrm{O}$ economista norte-americano Milton Friedman (1962) defendia a renda mínima na forma de imposto de renda negativo ao invés de transferência de renda como a maneira mais eficaz de combate à pobreza. Sua proposta resultou na adoção do Crédito Fiscal por Remuneração Recebida (Earned Income Tax Credit - EITC) em 1974, nos Estados Unidos.

${ }^{3}$ O filósofo e economista belga Philippe Van Parijs é o grande defensor da proposta de Renda Básica (Parijs, 1992) que consiste na transferência monetária a todos os indivíduos de determinada sociedade indiscriminadamente. Tal programa de atendimento universal deveria ser financiado por meio da taxação de ricos e, assim, culminar numa melhor distribuição de renda e também na ampliação da liberdade.

${ }^{4}$ Verificação no sítio eletrônico mmm.ipc-undp.org no dia 20 de agosto de 2010.

${ }^{5}$ Para mais informações sobre experiências internacionais, consulte o site eletrônico da Basic Income Earth Network (BIEN) no http://www.basicincome.org/bien/aboutbien.htm.

${ }^{6}$ Criado pela Medida Provisória no 132 de 20/10/2003, posteriormente convertida na Lei ${ }^{\circ}$ 10.836 de $9 / 1 / 2004$.

${ }^{7}$ Programa Nacional de Renda Mínima vinculada à educação - Bolsa Escola (Lei no 10.219/ 2001), do Programa Nacional de Acesso à Alimentação - PNAA (Lei no 10.689/2003), do Programa Nacional de Renda Mínima vinculada à saúde - Bolsa Alimentação (Medida Provisória no 2.206-1/ 2001), do Programa Auxílio-Gás (Decreto no 4.102/2002) e do Cadastramento Único do Governo Federal (Decreto no 3.877/2001). Câmbio US\$ em abril de 2011.

${ }^{8}$ Ministério do Desenvolvimento Social e Combate à Fome. A Evolução dos Recursos dos Programas de Transferência de Renda. Caderno SUAS, Ano 3, n 3, Brasília: 2008. Câmbio US $\$$ em abril de 2011.

${ }^{9}$ Dados referentes ao ano de 2007.

${ }^{10}$ Diario Oficial Segunda Sección de 8 de marzo de 2005.

${ }^{11}$ Dados referentes ao ano de 2006.

${ }^{12}$ Embora a legislação mais atual é a Ley 19949 de 05 de junio 2004.

\section{Referências bibliográficas}

BARDACH, Eugene. Implementation Game: What Happens After a Bill Becomes a Law. Mit Studies in American Politics and Public Policy, 1977.

Bastagli, Francesca. The Design, Implementation and Impact of Conditional Cash Transfers Targeted on the Poor: An Evaluation of Brazil's Bolsa Familia. PhD Thesis, London School of Economics and Political Science, 2008a.

. Conditionality in Public Policy Targeted on the Poor. Social Policy and Society, v. 1, no 8, p. 127-140, 2008b.

. From Social Safety Net to Social Policy? the role of conditional cash transfers in welfare state development in Latin America. International Policy Centre for Inclusive Growth Working Paper 60, Brasília, 2009.

BRiTTO, Tatiana. Recent Trends in the Development Agenda of Latin America: an analysis of conditional cash transfers. Ministry of Social Development, mimeo, Brasília, 2005.

. Panorama Social de América Latina 2009. Santiago: CEPAL, 2009. 
Cohn, Amélia; FonsecA, Ana. O Bolsa-Família e a questão social. Revista Teoria e Debate, $\mathrm{n}^{\circ}$ 57, mar./abr. 2004.

CunHa, Rosani. Entitlement to Income in Brazil: the Experience of the Bolsa Familia Programme. Programa África-Brasil de Cooperação em Desenvolvimento Social. Brasília: International Policy Centre for Inclusive Growth, 2008.

Friedman, Milton. Capitalism and Freedom. Chicago: University of Chicago Press, 1962. Lício, Elaine. A trajetória dos programas de transferência de renda no Brasil: o impacto da variável federativa. Revista do Serviço Público, Brasília, ENAP, Ano 55, n 3, jul.-set., 2004.

Lindert, Kathy; Linder, Anja; HobBs, Jason; De La BriÈre, Bénédicte. The Nuts and Bolts of Brazil's Bolsa Família Program:Implementing Conditional Cash Transfers in a Decentralized Context. Social Protection Discussion Paper n 709, Washington DC, World Bank, 2007.

LinderT, Kathy; SkOufias, Emmanuel; Schapiro; Joseph. Redistributing Income to the Rich and Poor: Public Transfers in Latin America and the Caribbean. Social Protection Working Paper 0605, Washington DC, World Bank, 2006.

Medeiros, Marcelo. A trajetória do Welfare State no Brasil: o papel redistributivo das políticas sociais nos Anos 1930 a 1990. Texto para discussão, n 852. Brasília: IPEA, 2001.

Medeiros, Marcelo; Britto, Tatiana; Sones, Fabio Veras. Targeted Cash Transfer Programmes in Brazil: BPC and the Bolsa Família. IPC-IG Working Paper 46. Brasília: International Policy Centre for Inclusive Growth, 2008.

Ministério do Desenvolvimento Social e Combate à Fome. Pesquisa de Avaliação de Impacto do Programa Bolsa Familia. Belo Horizonte: Cedeplar, 2005.

Pressman, Jeffrey; Wildavsky, Aaron. Implementation. Berkeley: University of California Press, 1973.

Rawls, John. A Theory of Justice. Cambridge, Mass.: Harvard University Press, 1971.

SEn, Amartya, Poverty and Famines: An Essay on Entitlements and Deprivation.Oxford: Clarendon Press, 1982.

. Commodities and Capabilities. Oxford: Oxford University Press, 1985.

SoAres, Fabio Veras; Ribas, Rafael Perez; Osório, Rafael Guerreiro. Avaliando o Impacto do Programa Bolsa Família: uma comparação com programas de transferência condicionada de renda de outros países. IPC evaluation note, $\mathrm{n}^{\circ} 1$. International Policy Centre for Inclusive Growth, 2007.

SoAres, Sergei Suarez; Osório, Rafael Guerreiro; Soares, Fabio Veras; Medeiros, Marcelo; ZePedA, Eduardo. Conditional Cash Transfers in Brazil, Chile and Mexico: Impacts upon Inequality. Working Papers 35, International Policy Centre for Inclusive Growth, 2007.

Suplicy, Eduardo; Cury, Samir. A Renda Mínima Garantida como proposta para remover apobreza no Brasil. Revista de Economia Política, v. 14, n 1, 1994.

Suplicy, Eduardo. Renda de Cidadania: a saída é pela porta. São Paulo: Cortez, Fundação Perseu Abramo, 2002.

Van PArijs, Philippe (Ed.). Arguing for a basic income. London: Verso, 1992.

Villatoro, Pablo. Programas de transferências monetárias condicionadas: experiências em América Latina. In: Revista de la CEPAL, n 86, 2005. 


\section{Resumo-Resumen-Abstract}

\section{Programas de Transferência Condicionada de Renda na América Latina: uma abordagem comparada entre Brasil, México, Chile e Colômbia \\ Pedro Luiz Costa Cavalcante}

$\mathrm{O}$ artigo desenvolve um estudo comparado qualitativo acerca das Políticas de Transferência Condicionada de Renda na América Latina. Esta modalidade de política, considerada a mais nova geração das políticas sociais, compartilha três componentes básicos: transferência monetária direta ao cidadão ou família; foco nos segmentos mais pobres e a cobrança de condicionalidades. Na última década, seus impactos sobre a melhoria das condições de vida da população têm chamado a atenção de governos, organismos multilaterais e do meio acadêmico. Todavia, a literatura tem focado predominantemente na análise dos seus impactos e menos nos fatores relativos à operacionalização desses programas. Por isso, o objetivo principal do artigo é descrever as estruturas de funcionamento dessas políticas, haja vista sua influência sobre os seus resultados. Para fins de comparação são selecionados os programas dos governos do Brasil, México, Chile e Colômbia, uma vez que são as experiências mais consolidadas da região. $\mathrm{O}$ trabalho conclui que embora os modelos de implementação sejam bastante diversificados, todos compactuam com a percepção multidimensional da pobreza e, portanto, seu enfrentamento demanda ações de caráter intersetorial. Ademais, os bons resultados na focalização desses programas são consequência da priorização de estratégias de descentralização que potencializam a coordenação e cooperação nas ações governamentais.

Palavras-Chave: Políticas Públicas; Implementação; Programas de Transferência Condicionada de Renda; América Latina.

\section{Programas de Transferencias Condicionadas en América Latina: un abordaje compara- do de Brasil, México, Chile y Colombia}

Pedro Luiz Costa Cavalcante

El artículo desarrolla un estudio cualitativo comparativo sobre las políticas de transferencias monetarias condicionadas en América Latina. Este tipo de política, considerada la más nueva generación de políticas sociales, comparte tres componentes básicos: las transferencias de dinero directamente a la persona o la familia, enfoque en los más pobres y el requisito de las condicionalidades. En la última década, su impacto en la mejora de las condiciones de vida de la población ha llamado la atención de gobiernos, organizaciones multilaterales e instituciones académicas. Sin embargo, la literatura se ha centrado fundamentalmente en el análisis de sus impactos y en menor medida en los factores relacionados con la operación de estos programas. Por lo tanto, el objetivo de este artículo es describir las estructuras de funcionamiento de estas políticas, debido a su influencia en los resultados. Para efectos de comparación son seleccionados los programas de los gobiernos de Brasil, México, Chile y Colombia, ya que implican las experiencias más consolidadas de la región. La encuesta concluye que, pese a sus diversidades, los programas comparten la percepción multidimensional de la pobreza y por esto su enfrentamiento debe ser realizado por acciones intersectoriales. Por otra parte, el éxito en la focalización de estos programas es consecuencia de la priorización de la descentralización que mejora la coordinación y la cooperación en las acciones del gobierno.

Palabras clave: Políticas Públicas; Implementación; Programas de Transferencia Condicionada de Renta; América Latina. 


\section{Conditional Cash Transfer Programs in Latin America: a comparative approach of Brazil Mexico, Chile and Colombia}

Pedro Luiz Costa Cavalcante

The main purpose of this inquiry is to develop a qualitative comparative study on the implementation of conditional cash transfer policies in Latin America. This type of policy, known as the newest generation of social policies, congregates three basic components: cash transfers direct to citizen or family, focus on the poorest and the concept of conditionalities. Over the last decade, its impact on improving people's living has called the attention of governments multilateral organizations and universities worldwide. However, the literature has focused primarily on their impact analysis instead of the policy frameworks. Therefore, this article's goal is to describe the operational functioning of these policies, considering their high influence on the results. For comparison purpose, the national government programs of Brazil, Mexico, Chile and Colombia are selected since they are the most institutionalized initiatives in the region. As conclusion, the paper argues that even though the implementation frameworks are quite diverse, they all share the poverty multidimensional perception, which leads to undertake inter-sector actions. Moreover, positive outcomes of focalization are due to decentralization strategies that enhance coordination and cooperation among all government levels.

Keywords: Public Policy; Implementation; Conditional Cash Transfer Programs; Latin America.

Pedro Luiz Costa Cavalcante

Graduado, mestre e doutorando em Ciência Política pela Universidade de Brasília (UnB). Possui especialização em Administração Pública pela Escola Brasileira de Administração Pública e de Empresas (Ebape/FGV). É Especialista em Políticas Públicas e Gestão Governamental do Ministério do Planejamento e, atualmente, encontra-se de licença para o doutorado.

Contato: cavalcante.pedro@gmail.com 